\title{
Medida da Qualidade em Educação - apresentação de um modelo
}

Heraldo Marelim Vanna*

O problema da qualidade em educação é uma preocupação da sociedade como um todo. Subjacentemente, o conceito de responsabilidade educacional - educational accountability - permeia essa inquietação, ou seja, havendo pessoal qualificado, condições matcriais, instrumental instrucional, metodologias e estratégias adequadas, a educação formal deveria ser, necessariamente, de boa qualidade. Isso, entretanto, nem sempre ocorre, pois uma complexa rede de variáveis atua no processo e cria um quadro de elementos interferentes que determinam níveis diversos de excelência educacional.

Algumas indagaçöes surgem de imediato: como conceituar qualidade em educação? Será possível uma definição operacional de qualidade em educação a fim de mensurá-la com adequação? O problema precisa ser analisado e discutido com a participação da comunidade educacional e de elcmentos da sociedade. A medida da qualidade em educação, entretanto, não pode ficar restrita apenas ao desempenho escolar, necessita, também, verificar outras variáveis que se associam e condicionam o rendimento escolar. $\mathrm{O}$ que as crianças fazem na escola, o que os professores procuram transmitir aos seus alunos e o que os livros didáticos apresentam refletem expectativas culturais e educacionais da sociedade, bem como seus valores e seus objetivos sociais e econômicos. Assim, é impositivo verificar cm que medida a interaçäo dessas variáveis contribui para a qualidade da educação.

É necessário reiterar que a avaliação da qualidade da educação nāo se limita apenas à verilicação do rendimento escolar, que é um momento na caracterização dessa qualidade. $O$ desempenho dos estudantes em pesquisas da qualidade da educaçāoé melhor comprecndido e interpretado quando se levantam informaçöes sobre o tipo de ensino que reccbem, os procedimentos que vivenciam em sala de aula e no colégio, e ainda sobre as características ambientais da famflia que determinam o seu comportamento. Assim, a pesquisa sobre a

- Do Departamento de Pesquisas Educacionais da Fundaçăo Carlos Chagas 
qualidade da educaçäo precisa caracterizar o contexto nacional em que o processo educacional se desenvolve, identificar criticamente os fatores näo diretamente ligados à escola que afetam a educaçăo e analisar a ação da escola em termos de entrada, processo $e$ produto.

A avaliação da qualidade da educação deve, necessariamente, partir de uma análise do contexto nacional, envolvendo as características da população, os seus valores culturais, os investimentos financeiros em educaçäo e a organização das escolas. As caracteristicas da população não se devem limitar a estatísticas demográficas, mas apresentar e discutir os vários níveis de educação, o processo de transformaçăo da economia e a composição da força de trabalho, assim como suas tendências. Os valores culturais da sociedade precisam ser identificados, destacando-se, particularmente, a problemática da maior ou menor valorizaçäo da educação, o papel da educação no desenvolvimento individual e na formaçáo profissional, as oportunidades educacionais oferecidas pela sociedade e 0 grau de universalizaçäo da educação; além disso, problemas cruciais como o do status do professor na sociedade e a responsabilidade da famf́lia na educação necessitam também ser considerados. Os investimentos financeiros em educação năo podem deixar de ser considerados como uma das importantes variáveis que influenciam na qualidade da educaçăo, juntamente com a alocaçăo de recursos humanos qualificados para a área educacional. Finalmente, no quadro do contexto nacional, a avaliaçăo da qualidade da educaçảo deve considerar a organização do sistema escolar, identificando os diversos tipos de escola, os graus de centralizaçäo administrativa, a influência do processo de seletividade social na escola e a organizaçāo do sistema de avaliação, que, dependendo da sua filosofia e da sua estruturaçäo, pode criar diferentes tipos de impedimentos, com amplas repercussões sociais.

A criança, e mesmo o adolescente, na maioria dos casos, passa um tempo extremamente reduzido na escola; desse modo, a fim de avaliar a qualidade da sua educação, é fundamental que sejam considerados os fatores näo diretamente ligados à escola, que compreenderäo, entre outros aspectos, o status sócio-econômico da famflia, o nível de educaçāo dos pais, os recursos educacionais no lar, o interesse e a participaçāo dos pais no processo educacional, as atividades educacionais fora da escola, as atividades de lazer e sociais (televisảo, esportes e interação de grupos) e, ainda, uma análise das atitudes e das aspiraçōes dos estudantes.

A investigação sobre a qualidade da educação envolve, naturalmente, uma discussåo aprofundada da variável escola, que, no presente modelo, deve sofrer uma abordagem em termos de entrada, processo e produto. A partir dessa perspectiva, para a configuraçäo do fator entrada, é desejável a identificaçăo e análise das variáveis tamanho e tipo de escola; extensão do ano letivo e da jornada escolar; tamanho, características e experiência do pessoal docente; qualidade das instalações escolares; organizaçăo dos programas escolares; e, finalmente, a participaçäo dos pais na vida escolar.

A parte do modelo mais diretamente relacionada à sala de aula, ao que é ensinado e como é ensinado, no seu conjunto, engloba as variáveis processo, que se centram na avaliação do currículo e das práticas instrucionais. A avaliação do currículo visa, particularmente, a análise dos objetivos e dos conteúdos programáticos, procurando identificar em que medida sảo destacados fatos, conceitos $\mathrm{e} / \mathrm{ou}$ habilidades complexas. Ainda na variável processo, o conjunto das práticas instrucionais procura identificar o tipo de instrução ministrada (em grandes e pequenos grupos e/ou instruçâo programada); a ocorrência de aulas expositivas, demonstrações e/ou discussöes; o uso de material didático (impressos e equipamentos); a natureza das tarefas a serem realizadas em casa; e, 
finalmente, a critica das práticas docimologicas, ou seja, a analise do planejamento e da execução da avaliaçẫo escolar.

O presente modelo completa-se com a avaliação da variável produto, concentrada no desempenho escolar e na formação de atitudes associadas ao processo educacional, momento em que seräo empregados diferentes instrumentos de mensuraçäo escolar, inclusive, testes de escolaridade e questionários de atitudes.

Um projeto de avaliação da qualidade da educação, dessa forma, deve relacionar o desempenho dos estudantes a contextos culturais e a práticas educacionais associadas ao rendimento escolar. Surge, assim, um grave problema a ser discutido - a validade dos instrumentos, particularmente a validade dos testes de escolaridade.

O uso de testes sem a observância da teoria das medidas contribui para que sejam. negligenciadas importantes características dos instrumentos aplicados à mensuração dos atributos humanos. Diferentes testes possuem diferentes virtudes e näo existe um teste que seja a melhor para todos os propósitos. Um teste é sempre constrú́do com uma determinada finalidade, não havendo, portanto, um único instrumento que seja capaz de medir de modo globalizado as dilerentes dimensōes do homem. Assim, ao construir um teste, é necessário que se identifique o objetivo do instrumento e em que situação concreta será utilizado. Um teste para uso em sala de aula, com a finalidade de promover uma avaliaçäo formativa, não tem, certamente, as mesmas caracteristicas de um outro empregado para fins de seleção, quando se processa uma avaliaçäo somativa. Um teste serve, ainda, para um determinado contexto e para um fim especfíco, não tendo a mesma utilidade em outros contextos e para outros fins.

As questões relativas à validade dos testes educacionais são complexas e, freqüentemente, sujeitas a controversias, que, entretanto, precisam ser enfrentadas a fim de solucionar os problemas relativos à construção dos instrumentos de medida, à sua análise empírica e ao julgamento do seu valor como elementos capazes de medirem, eficientemente, os atributos definidos no planejamento.

$O$ processo de avaliaçăo de um teste possui uma lógica propria, ressaltando-se, entretanto, que a validação de um teste depende do uso que dele se pretenda fazer. Um teste nunca possui um único e exclusivo objetivo; desse modo, não se pode assegurar que um teste seja válido em termos gerais. A validação de um instrumento de medida educacional está, pois, relacionada com a interpretaçăo que ao mesmo se pretenda dar.

A validade de um instrumento de medida está associada à concretização dos seus objetivos. Assim, no caso especffico de um teste de desempenho escolar, a validade é positivada na medida em que esse instrumento realiza aquilo a que se propuseram seus construtores. $O$ conceito de validade, entretanto, $E$ multifacetado, não sendo possível dizer, a priori, se um teste é ou não válido: - um teste pode ser válido para um currículo e não o ser para outro; um teste pode ser válido para um grupo, mas não para outro. $A$ validade năo $\hat{E}$, pois, um atributo que se possa apresentar em termos gerais; é sempre específica a um instrumento, a um curso, a um currículo, a um professor e a um grupo de individuos com características bem definidas.

$O$ processo de validaçäo presta-se a diferentes interpretações muitas vezes conflitantes entre si, sendo necessário, por conseguinte, maiores esclarecimentos sobre sua natureza. Valida-se não propriamente o teste mas a interpretação dos dados decorrentes de um procedimento específico. Um mesmo teste pode ser usado para diferentes fins e a cada aplicaçăo do instrumento pode corresponder, portanto, uma interpretaçăo dos resultados. Ora, considerando que cada interpretaçăo tem seu próprio grau de validade, 
nāo é possível afirmar que um teste é válido em geral, pois a validade é sempre especifica. Um teste, em síntese, possui muitas validades; conseqüentemente, há necessidade de aprofundar e estender os estudos de validaçāo para que se possa determinar as diversas dimensōes da sua validade.

O problema da validação dos instrumentos deve receber tratamento prioritário no processo investigativo da qualidade da educação, conforme a análise anterior. $O$ uso indiscriminado de instrumentos de avaliação pode levar a conclusōes inteiramente falaciosas, com amplas repercussōes. Nesse momento, cabem algumas indagaçöes referentes ao contexto educacional brasileiro: - os instrumentos usados para fins de avaliação educacional possuem validade empiricamente verificada? Os instrumentos usados pelos professores possuem validade curricular? Os instrumentos empregados no dia-a-dia da escola possuem validade de conterido? $\mathrm{E}$, finalmente, uma pergunta dolorosa: - os altos indices de reprovaçāo nas primeiras séries do $1^{2}$ grau não decorreriam em parte da falta de validade dos instrumentos usados na avaliação? São questôes que precisariam ser respondidas no processo de investigação da qualidade da educação. 


\section{ANEXO \\ Medida da Qualidade \\ em Educação}

esquema de um modelo

\subsection{CONTEXTO NACIONAL}

1.1. Características da populaçäo

1.1.1. Estatísticas demográficas

1.1.2. Niveis de educação

1.1.3. Transformaçōes da economia

1.1.4. Força de trabalho

1.2. Valores culturais

1.2.1. Valorização da educação

1.2.2. Desenvolvimento individual

1.2.3. Formaçäo profissional

1.2.4. Oportunidades educacionais

1.2.5. Universalização da educação

1.2.6. Status do professor

1.2.7. Responsabilidade da familia na educação

13. Investimentos financeiros

1.3.1. Alocação de recursos humanos

1.4. Organização da escola

1.4.1. Tipos de escola

1.4.2. Centralização administrativa

1.4.3. Seletividade social

1.4.4. Sistema de avaliação 


\subsection{FATORES NÃO DIRETAMENTE LIGADOS À ESCOLA}

2.1. Status sócio-econômico da família

2.2. Nivel de educação dos pais

2.3. Recursos educacionais no lar

2.4. Participaçăo dos pais no processo educacional

2.5. Atividades educacionais fora da escola

2.6. Atividade de lazer e soclais

2.7. Atitudes e aspiraçóes dos estudantes

\subsection{ESCOLA}

3.1. Entrada

3.1.1. Tamanho e tipo da escola

3.1.2. Extensāo do ano letivo e da jornada escolar

3.1.3. Tamanho, características e experiência do corpo docente

3.1.4. Qualidade das instalaçōes escolares

3.1.5. Organização dos programas escolares

3.1.6. Participação dos pais na vida escolar

3.2. Processo

\subsubsection{Curriculo}

3.2.1.1. Análise de objetivos e conteúdos programáticos

3.2.2. Práticas instrucionais

3.2.2.1. Tipos de instruçã̀o

3.2.2.2. Aulas expositivas, demonstraçōes e/ou discussōes

3.2.2.3. Uso de material didático

3.2.2.4. Tarefas de casa

3.2.2.5. Avaliação escolar

33. Produto

33.1. Desempenho escolar

3.3.2. Formaçäo de atitudes 